Etnográfica

Revista do Centro em Rede de Investigação em

Antropologia

vol. $22(2) \mid 2018$

Vol. 22 (2)

\title{
Formas de "buscar Deus" e de ser assediado pelo demônio: objetos na vida de católicos brasileiros
}

"Seeking God" and being harassed by the Devil: objects in the life of Brazilian Catholics

\section{Ypuan Garcia}

\section{(2) OpenEdition}

Journals

Edição electrónica

URL: https://journals.openedition.org/etnografica/5312

DOI: 10.4000/etnografica.5312

ISSN: 2182-2891

\section{Editora}

Centro em Rede de Investigação em Antropologia

Edição impressa

Data de publição: 1 junho 2018

Paginação: 259-280

ISSN: 0873-6561

\section{Refêrencia eletrónica}

Ypuan Garcia, «Formas de "buscar Deus" e de ser assediado pelo demônio: objetos na vida de católicos brasileiros», Etnográfica [Online], vol. 22 (2) | 2018, posto online no dia 07 julho 2018, consultado o 19 janeiro 2022. URL: http://journals.openedition.org/etnografica/5312 ; DOI: https:// doi.org/10.4000/etnografica.5312

\section{(c) (i) (8)}

Etnográfica is licensed under a Creative Commons Attribution-NonCommercial 4.0 International License. 


\section{Formas de "buscar Deus" e de ser assediado pelo demônio: objetos na vida de católicos brasileiros}

\section{Ypuan Garcia}

Este artigo propõe refletir sobre o modo como objetos propiciam, simultaneamente, a "busca por Deus" e o assédio pelo demônio entre católicos na cidade de São Paulo. Se, por um lado, o mal ataca por meio de uma ampla gama de objetos, sua neutralização se dá pela bênção de outros: sal, água, óleo de cozinha, roupas e documentos abençoados por um sacerdote. Discuto a importância dos objetos na "busca" e no assédio, uma vez que ocultam e revelam presenças divinas e maléficas por meio das "intenções" que aderem a eles ao longo das trocas em que tomam parte.

PALAVRAS-CHAVE: catolicismo, objeto, intenção, troca.

"Seeking God" and being harassed by the Devil: objects in the life of Brazilian Catholics - This article discusses how objects provide both the "search for God" and the risk of capture by the Devil among Catholics in the city of São Paulo. Whereas evil attacks through a wide range of objects, its neutralization occurs through the blessing of others: salt, water, cooking oil, clothes and documents blessed by a priest. It is argued that objects are important both to the "search" and the harassment because they are able to conceal and reveal divine and evil presences in accordance with the "intention" that adheres to them through the exchanges in which they take part.

KEYWORDS: Catholicism, object, intention, exchange.

GARCIA, Ypuan (ypuangarcia@gmail.com) - Núcleo de Antropologia da Política, do Estado e das Relações de Mercado (NAPER), Universidade Federal do Paraná (UFPR), Brasil. 


\section{INTRODUÇÃO}

Neste artigo debato algumas questões acerca das formas de existência dos objetos no cotidiano de católicos na cidade de São Paulo. ${ }^{1}$ A finalidade é abordar como a proximidade e o contato anterior com "intenções" desconhecidas e tidas às vezes como "malignas" os transformam e os levam a sofrer intervenções posteriores, seja por meio da bênção sacerdotal, seja através de outra forma material que a contenha, como a água benta.

Entre alguns católicos em São Paulo, a grande metrópole brasileira, não é incomum que as experiências cotidianas das presenças divinas e malignas sejam abundantes. Água, alimentos e roupas podem ser tanto meios pelos quais Deus se deixa "buscar" quanto recursos de que o diabo lança mão para assediar quem quer que seja. As pessoas estariam em meio à guerra perene entre entes celestiais e infernais. Esse combate, no entanto, se desdobra de maneira sutil e através de ocorrências ordinárias. Por esse motivo, a procedência dos objetos que são ofertados às pessoas é alvo de atenção rigorosa.

Essa cautela, entretanto, não impede algo crucial: esses católicos estão envolvidos com a insondabilidade dos desígnios de Deus (que, como dizem, "está em tudo") e com a perseverança dos sortilégios do diabo (que "pode estar em tudo"). Esses seres estão ou podem estar em todos os lugares, o que define o caráter extraordinário das suas ações. Estas não correspondem ao inefável ou à sua redução a uma "linguagem religiosa" ou "ritual" (Keane 1997), mas à infinidade de suas manifestações. ${ }^{2}$

Esse breve esboço advém de três anos de pesquisa etnográfica intermitente, entre 2013 e 2016, com uma comunidade católica paulistana, a Missão Eucarística Clamor dos Pobres $^{3}$ (doravante Missão), fundada em 2009 (Costa 2017). Por ser uma "comunidade de vida e aliança" (Mariz 2006; Carranza e Mariz 2009), absorve pessoas que fazem votos de castidade (celibatários que dividem lares masculinos ou femininos e recebem os títulos de frei ou freira), leigos solteiros e casados, e simpatizantes com sua forma de vida, incluindo os padres que a recebem em suas paróquias.

A Missão é uma forma associativa oriunda da passagem dessas pessoas pela Renovação Carismática Católica, um movimento que se destaca pela incorporação de práticas pentecostais ao catolicismo através da ênfase na proliferação dos "dons do Espírito Santo": cura, palavra de ciência, libertação de demônios, glossolalia etc. (Csordas 1994, 1997; Carranza 2000). Digo de antemão que a finalidade deste artigo não é investigar estritamente essa

1 Agradeço a Otávio Velho pelo apoio na preparação da versão final deste texto.

2 As traduções dos textos e dos termos em língua estrangeira são de inteira responsabilidade minha.

3 Os nomes são, em sua maioria, pseudônimos. 
comunidade. Se o ponto de partida empírico é um coletivo ${ }^{4}$ de pessoas que se definem majoritariamente como "católicas", e que abrange missionários e não missionários, o catolicismo - em sua vertente carismática - é a matriz cristã a ser analisada, por meio de dois eixos de problemáticas: a proliferação de análises antropológicas do cristianismo (Robbins 2003, 2011 ; Cannell 2006; Garriott e O'Neill 2008) e a atenção renovada aos objetos, o que coincide com a "rematerialização" dos estudos da religião (Houtman e Meyer 2012). ${ }^{5}$

O texto divide-se em quatro seções. A primeira consiste em um breve retorno ao lugar de onde parti quando me pus a pensar em objetos. A segunda aponta em que medida a atenção destinada à análise dos mesmos é também uma possibilidade de gerar novos conceitos. A terceira tem por finalidade escapar de um impasse que acompanha as preocupações acerca do lugar analítico das formas materiais. A quarta aborda as maneiras de "buscar Deus" e de ser assediado pelo demônio através das "intenções" que aderem ao que é tangível. Por fim, a conclusão esboça como uma visada nos objetos é simultaneamente um modo de realçar como se define a pessoa entre esses católicos.

\section{“O OBJETO EM SI PODE SER QUALQUER COISA...}

\section{QUALQUER COISA QUE SEJA LIGADA DIRETAMENTE À PESSOA"}

Quando conheci Ricardo, em 2013, ele detinha o título de frei e o nome correspondente: Irmão Leone Alegria dos Pobres. Depois de alguns anos vivendo como religioso, interessou-se por uma moça, Joyce, que na época se preparava para a vida celibatária. Decidiu, em 2014, abdicar do "voto de castidade", pois tinha a pretensão de se casar. Por ser o frei decano da Missão e um postulante ao sacerdócio, a situação causou mal-estar. A mudança no "estado de vida" - do celibato ao namoro - surpreendeu a muitos. A "crise vocacional" foi descrita, primariamente, como um ataque, uma "cilada do demônio". Ricardo e Joyce continuaram missionários. Compareci à cerimônia de casamento, já em 2015, pois Ricardo tornou-se um amigo. Fiquei, desde aquele dia, intrigado com a "lembrança do casamento", um pequeno mimo que os noivos, além da festa, ofertaram aos seus convidados.

A pequena garrafa contém aproximadamente $20 \mathrm{ml}$ de água benta. No rótulo, leem-se apenas as letras iniciais dos nomes do casal e a data do

4 O conceito de "coletivo" é um empréstimo de Bruno Latour (2001 [1999]) e tem como desígnio sublinhar, para além da noção de sociedade, um cosmo habitado por meio das associações entre humanos e não humanos. As pessoas lançam mão do termo "comunidade", mas não se trata de uma comunidade estritamente humana, e sim de vínculos constituídos entre seres com naturezas distintas: Deus, Jesus Cristo, o Espírito Santo, a Virgem Maria, os santos, os anjos e os adeptos.

5 Não pressupomos que a religião é uma unidade de análise congelada, homogênea e trans-histórica (Asad 2010 [1993]: 264). 
casamento: “11/07/2015”. Aproximadamente duas centenas desses regalos estavam dispostas, ao lado da pista de dança, na comemoração que sucedeu à solenidade. Passada a lua de mel, estive com Ricardo rapidamente. De maneira corriqueira, ele me contou que a finalidade de dar a água benta era ir além de uma simples lembrança, mas ofertar algo que as pessoas pudessem "usar". Foi solicitado a um padre que "abençoasse a água" para que as pessoas pudessem aspergi-la em suas residências, locais de trabalho, automóveis etc. Afora o líquido, havia uma dezena do terço que, por caber no bolso, poderia ser facilmente transportada para as orações diárias, de modo que os convidados incluíssem o novo casal nas suas preces. Ricardo não

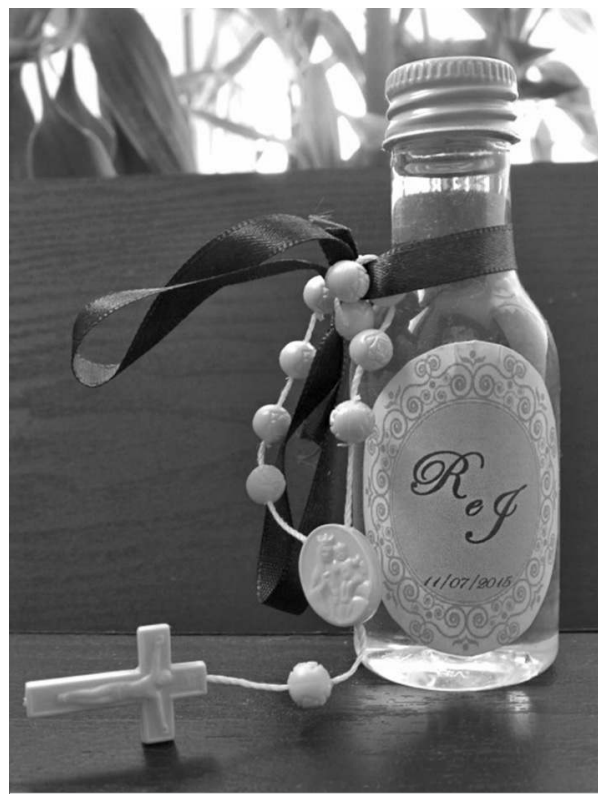

Fotografia 1 - "Lembrança do casamento". Fotografia: Ypuan Garcia, 2015. escondia, entretanto, que para muitos o regalo jamais teria esses destinos.

A lembrança movimentava algo geral acerca do ato de presentear entre essas pessoas. Ricardo acentuou que durante e posteriormente à festa de casamento recebeu inúmeros presentes. Alguns deles não vieram com o nome de quem realizou o ato de afeto e carinho. A omissão conduziu ele e Joyce a "rezarem [aspergindo água benta]" alguns presentes, como roupas e roupa de cama, que ele definia como "objetos do nosso uso, pessoais". Com isso em perspectiva, observou que nos dias posteriores ao matrimônio foi brindado com um par de canetas. Este não foi dado diretamente pela pessoa que o ofertou, mas por um amigo de seu amigo:

"Ele ganhou de alguém e ele deu pra mim. Então, eu não sei quem foi a pessoa que deu para ele essa caneta. Não sei qual foi a procedência, porque tem muita gente que leva muito objeto, uma caneta, e faz algum tipo de magia... A pessoa que faz isso está intencionada em fazer o mal. Tem muito mais a intenção. Você dá alguma coisa com o mal para a pessoa".

Sua inquietação não era sem motivo, pois na vida desses católicos uma ação maléfica, muitas vezes, acontecia por meio de artimanhas que, a princípio, se caracterizavam pela invisibilidade. Meu amigo simplesmente me dizia que era preciso permanecer atento ao assédio do demônio. Ele não teria a mesma "precaução" (Garcia 2014: 8, n. 10) se soubesse quem era 
a pessoa e estivesse plenamente ciente da "intenção do coração" dela para com ele. ${ }^{6}$

Essas observações permitem abordar o que propicia que a água e a caneta se tornem potencialmente benfazejas ou perigosas. Pode-se admitir que não "estão" (uma condição) inertes. A possível exotização efetuada pela análise estaria na presunção de que a água e a caneta "sejam" (dois entes), entre outros atributos, dotadas de interioridade, de intencionalidade. Elas pareceriam portar uma faculdade que as tornaria protetivas (a água) ou danosas (a caneta). A trivialização corresponderia à redução do termo "uso", nos dizeres de Ricardo, à maneira como essas pessoas lidam com a troca de bens alienáveis em uma economia em que prevalece o "indivíduo" (Gregory 1982, apud Laidlaw 2000: 620).

Enquanto estive com meu amigo, poderia prosseguir fazendo as seguintes interrogações: O que é esse objeto para você? Por que ele é importante? Qual o significado dele? As três indagações alcançariam possivelmente as seguintes redundâncias analíticas: "Os objetos produzem as pessoas, porque possuem intencionalidade, espiritualidade"; ou, então, como bem aponta Marilyn Strathern, conduziriam a afirmar que "algum processo social, tal como o "ritual' " (2013 [1990]: 171), revelaria sua importância. Desse modo, decidi simplesmente inquirir: "Afinal, o que tem neles?" Sem hesitar, ele replicou: "Nada".

A resposta não causa estupor e coincide com a inferência geral na vida desses católicos de que "água em si é água” e "caneta em si é caneta”. Elas são transformadas em algo diferente de si através da bênção sacerdotal e da "intenção" que determina os efeitos que elas deverão causar naqueles a quem são endereçadas. Essas pessoas dizem geralmente que a água e a caneta tornam-se "veículos" e/ou "instrumentos" de propósitos benfazejos e maléficos, isto é, objetos "abençoados" e "consagrados". Os primeiros portam apenas a graça divina. Os segundos podem ser tanto benéficos ("bentos") quanto malignos (“contaminados"). O vocábulo consagração é uma estenografia católica para estados mutuamente exclusivos. Se a bênção suscita exclusivamente a proteção contra as forças demoníacas, a intenção (o propósito de um ato) pode ser, por assim dizer, divina, infernal e humana.

Esse tripé é fundamental para a definição do que é um “objeto”. Ricardo, como muitos de seus "irmãos" autodeclarados católicos, definia-o duplamente: "Objeto em si pode ser qualquer coisa [e] qualquer coisa que seja ligada diretamente à pessoa". Na primeira sentença, pode ser inerte ou passivo. Na segunda, torna-se potencialmente mais que uma coisa, considerando a sua vizinhança com seres e intenções diversos. Isto é, o objeto pode ser o índice material

6 A conversa com Ricardo em muito faz recordar, por justaposição, a passagem clássica acerca da troca que Marcel Mauss analisou, partindo do intelectual maori Tamati Ranaipiri (Best 1909, apud Mauss 2003 [1925]: 197-198). Retomo mais adiante o trecho célebre. 
(Webster 2013: 380) da intenção. Todavia, como veremos adiante, a pessoa também pode se tornar tal índice. Intenções são benéficas ou maléficas porque seu alcance inclui a premissa de que a proximidade absorve o item, quem o ofertou e a pessoa a quem ele se destina. Por sua vez, uma ação humana pode ser também o "veículo" e/ou "instrumento" pelo qual se realiza uma finalidade de Deus ou do diabo.

Se a água e a caneta em si mesmas são água e caneta, não é incomum que esse juízo acerca das mesmas se expanda para todo tipo de artefato, incluindo os religiosos. Ostensórios e hóstias, antes de serem consagrados e/ou abençoados, são respectivamente uma peça de ourivesaria e uma mistura de farinha com água. Devemos levar em consideração que estamos lidando com um modo de existência em que as pessoas estão ininterruptamente em contato com intenções humanas e não humanas. Nas últimas, reside um aspecto central: Deus é onipresente e o diabo é quase onipresente. Por se manifestarem indefinidamente em formas materiais cotidianas, não é possível determinar as ocasiões em que elas contaminam (são perigosas) ou não. Um objeto é considerado perigoso devido à impossibilidade de se estar imediatamente ciente da intenção que adere a ele. Antes de passar ao conceito de intenção, é fundamental realçar os desafios que aquela dupla definição do objeto coloca para a literatura antropológica sobre as formas materiais.

\section{INTERLÚDIO: O PROBLEMA DO CONCEITO}

A seção anterior trouxe à baila que um "objeto em si" pode ser tanto "qualquer coisa" quanto algo "ligad[o] diretamente à pessoa". A primeira afirmação realça que essas pessoas são igualmente "modernas" (Latour 1994 [1991]) e familiares quando assentam a assimetria entre elas e os objetos; já a segunda, que são diferentemente modernas e não familiares no modo de qualificar a assimetria, quando se referem à multiplicidade de intenções que parecem se acoplar aos objetos. Com isso em perspectiva, faço uma interrogação: será possível descrever a maneira como alguns católicos, situados no mundo moderno, estabelecem regimes específicos por meio dos quais lidam com as formas materiais?

Antes de tudo, estou levando em consideração que a religião cristã embebe, como se nota a partir do advento da "antropologia do cristianismo" (Robbins 2003), há pouco mais de dez anos, uma multiplicidade de estilos, devoções, perspectivas e denominações que passam por modificações imprevisíveis (Robbins 2004, 2007, 201 1; Cannell 2005, 2006; Keane 2007; Garriott e O’Neill 2008; Bialecki 2014, 2015). A análise empreendida aqui se localiza nos desdobramentos desses estudos recentes.

Dito isso, vou adiante com a pretensão de responder à pergunta. Desejo introduzir uma ideia que funcione, por assim dizer, em consonância com a 
emergência de outra problemática um pouco mais geral no seio da antropologia. Tornou-se um lugar-comum nas últimas três décadas certa desconfiança em relação a uma economia analítica fixada na cesura entre sujeito e objeto. Notemos que essa forma de exprimir o assunto diz respeito à admissão de um "espírito de época": a crise das grandes narrativas do significado (Ardener 1985). Se em algum momento os conceitos foram dotados de substância, nos últimos anos são exibidas as suas ficcionalidades. A discussão aqui compreende uma maneira específica de lidar com a definição de conceito. Há lugar, atualmente, para se tratar recursivamente de um conceito de conceito, dando conta, por exemplo, de sua qualidade "autotransformativa" (Gellner 2003, apud Corsín Jiménez e Willerslev 2007: 527-528).

Gregory Bateson, de quem adotarei a definição de conceito, já em 1958 antevia que os conceitos são modos de reunir "as peças do quebra-cabeça" (2008 [1958]: 312). Essa conclusão dizia respeito à premissa de que os "conceitos teóricos", a estrutura social, a economia, o ethos etc., abrangiam "uma ordem de realidade objetiva [mínima]. São realmente descrições de processos de conhecimento [...] mas sugerir que o 'ethos' ou a 'estrutura social' tem mais realidade que isso é cometer a falácia [...] da concretude deslocada [da hipóstase]" (G. Bateson 2008 [1958]: 312). Se posicionarmos os objetos para "nós" e os "objetos" para "eles", como eixos para aquelas "descrições", o exercício é passível de ser desenvolvido por meio de uma "hipótese $[\ldots]$ sistêmica $[\ldots]$ no sentido comunicacional e abdutivo [batesoniano]: há relações de comunicação, de conexão ["não óbvias"] que nós precisamos tentar identificar" (Velho 2007 [2002]: 328).

Tomando como ponto de partida que a definição do objeto como algo inanimado é familiar para fiéis e analistas, o desafio é retirar algumas implicações de justaposições realizadas a partir da ênfase em semelhanças conceituais. Estas não acarretam a diluição da diferença e a produção de identidades, mas sim o estabelecimento de "novas inferências" (M.C. Bateson 1988: 192) para além da exotização e da trivialização, já mencionadas no caso da água e da caneta. Com isso assinalado, nosso argumento se insere também em um debate corrente na antropologia acerca dos objetos, não obstante busque uma posição diferencial, como se verá adiante.

A profusão de abordagens diversas sobre as formas materiais, desde meados da década de 1980, é concomitante à redução sublinhada acima do poder de convencimento da cesura entre sujeito e objeto e à reflexão sobre a natureza dos conceitos. ${ }^{7}$ Não posso afirmar que a modificação nos termos das relações

7 A título de ilustração, eis algumas dessas abordagens: “a vida social das coisas” (Appadurai 2008 [1986]); a "ciência em ação" (Latour 2000a [1987]); a irredutibilidade dos artefatos ao contexto (Strathern 2013 [1990]) e, posteriormente, a preocupação com a “agência” (Gell 1998); a análise das coisas em termos heurísticos (Henare, Holbraad e Wastell 2007); ênfases nos materiais, [continua] 
entre "nós" e "eles" diversificou igualmente a maneira de descrever as coisas e os objetos "deles", mas sim que as recentes críticas aos divisores permitem que descrevamos aquilo que conta como objeto na vida das pessoas. Nas próximas páginas, vou ao encontro das similaridades que permitem produzir "novas inferências". Realço que os "conceitos teóricos" provindos da etnografia são irredutíveis às tentativas acadêmicas recentes de repensar as dicotomias entre sujeito e objeto, pessoas e coisas.

\section{JUSTAPOSIÇÃO E DIFERENÇA: OBJETO E COISA}

Historicamente, os cristãos exacerbam uma diferença porque tomam posições que concorrem com as "ideias modernistas sobre as quais a antropologia é fundada [...] [, tais como] os fundamentos da verdade e os limites da tolerância" (Robbins 2003: 192). A posição dos adeptos seria, em relação à disciplina, uma "mistura anômala do similar e do diferente" (Douglas 1966, apud Robbins 2003: 193). A condição indefinível dos seguidores de Jesus Cristo modifica, de imediato, o esquema canônico familiar/alienígena e leva, como veremos a partir de agora, a algumas justaposições.

Meus amigos católicos falavam corriqueiramente dos objetos como simples coisas inanimadas, apartadas de intenções desconhecidas ou contiguadas a elas. Há, independentemente disso, um debate acadêmico que repensa as noções de objeto e coisa. Notaremos adiante que as conceptualizações em ambos os lados têm origens e destinos diferentes. Se o sentido da hipótese, como já assinalado, é abdutivo, a conexão conceitual mais convincente para esta argumentação encontra-se naquilo que Claude Lévi-Strauss alcunhou, a partir do operador sacrificial, de "reino da continuidade" (2008 [1962]: 250). Em contraste com a experiência das pessoas com quem convivi, a importância atual da materialidade na discussão teórica é também uma tentativa incansável de reatar um vínculo desfeito com os entes materiais, cuja dissolução gerou um "déficit de contiguidade" (2008: 252) entre humanidade e mundo.

A "continuidade/contiguidade" sacrificial é trazida aqui à baila por seu valor heurístico, indicando que algo passa, vai adiante, para comunicar. O que está em questão é a "mediação real" (Castro 2002: 463) que o sacrifício mobiliza. Ela pode ser justaposta a outras imagens conceituais, "descrições de processos de conhecimento" (G. Bateson 2008 [1958]: 312), que se tornaram abundantes para lidar com a dissolução da cesura entre humanidade e natureza, ou mesmo com a negação de que ela tenha ocorrido.

[continuação] em lugar da materialidade (Ingold 2011 [2007]) etc. As implicações desse "material turn" (Houtman e Meyer 2012: 4-5) alcançam inclusive os estudos da religião, concentrando-se na necessidade de conferir atenção ao "real, ao mundo de objetos materiais e à textura do vivido" (2012: 4). A literatura é extensa, logo a aparição arbitrária desses autores atende aos propósitos da argumentação. 
A primeira dessas imagens é a inferência de que "[n]osso tecido não é mais inteiriço" (Latour 1994 [1991]: 13), devido à oficialidade da "purificação", em lugar da oficiosidade da "mediação" (Latour 1994 [1991]), à ênfase na qualidade dos "bons ou maus vínculos", em lugar da divisão entre "emancipação e alienação" no repertório moderno (Latour 2000b: 3). A segunda concerne às "linhas", em lugar dos "círculos", e às "reanima[ções] do pensamento" (Ingold 2006). A terceira, como realçam Amiria Henare, Martin Holbraad e Sari Wastell (2007: 2), embora com reservas, diz respeito à finalidade de "reintegrar a materialidade" às análises, o que se estabelece em Houtman e Meyer (2012). Essas imagens são fortes e persistem na discussão daquilo que estou chamando, a partir de Lévi-Strauss, de "escassez ou déficit de contiguidade".

$\mathrm{Na}$ vida dos católicos com quem estive, os conceitos ("descrições de processos de conhecimento") que a condição dos objetos abrangia não requeriam qualquer reconciliação com uma realidade definida anteriormente como externa. Dava-se quase o inverso. Importaria neutralizar o excesso de "proximidade", visto que objetos inanimados poderiam ser mais que meras coisas. Tendo em vista que as intenções eram muitas vezes desconhecidas, exigia-se o "discernimento": um dom divino que possibilita estabelecer os indícios de ações que provêm de Deus, do diabo e do "humano da pessoa", inclusive nos objetos. $^{8}$ Não era incomum que se discernisse através de uma pequena ação imediata. Quando, por exemplo, alguém recebia algum alimento, traçava sobre si o sinal da cruz ou discretamente nas bordas do prato onde ele havia sido depositado, pois não se estava a par da intenção de quem o oferecera. Dizia-se que era para "descontaminar" e, ao mesmo tempo, para "consagrar o alimento para Deus", dado que o assédio do demônio podia começar também pela ingestão de comida.

Devemos prosseguir com as justaposições. Desde Max Weber (1987 [1904]), a imputação do ascetismo aos cristãos criou, como bem nota Fenella Cannell, um obstáculo conceitual por conta de uma essencialização: alimentou a cesura entre mundanidade e transcendência, ao presumir que, ontologicamente, essa religião "desdenha da carne e do mundo material" (Cannell 2005: 338). Esses apontamentos realçaram a posição do protestantismo, ao revés do catolicismo, como vertente cristã analiticamente majoritária. A importância que os pensadores reformistas destinaram a formas devocionais desmaterializadas constituiu um dos alicerces da já desgastada definição moderna da religião. Esta proliferou a conclusão, por muito tempo generalizada e monolítica, de que os modos de vida cristãos renunciariam ao aqui e ao agora e dariam impulso ao capitalismo secular (Cannell 2005: 341) e ao individualismo moderno.

8 A expressão "humano da pessoa" muitas vezes é assimilada ao vocábulo "fraqueza”. A incompletude e o inacabamento da natureza humana tornam a pessoa, desde a expulsão do Paraíso, essencialmente "fraca". 
Reparemos que o último conecta-se em seu sentido abdutivo à promoção da "escassez de contiguidade". ${ }^{9}$

Meus amigos não se preocupavam com tal "escassez". O caráter incontornável da vicinalidade era o "dado", logo o distanciamento devia ser "construído". Em suas vidas, isso era marcado pela asserção de que viviam uma "missa continuada". O prolongamento da presença divina encontrava-se nos gestos ordinários daqueles que "caminham com Cristo": olhar, falar, ouvir etc., o que produz um deslocamento no próprio divisor entre Deus e matéria. Todavia, ser "habitado" pela divindade exigia que se demarcasse a todo momento que a pessoa "não é nada sem Deus", que "é tudo". Determinava igualmente não considerar que tudo vinha de Deus, mas que também poderia vir do demônio e do humano da pessoa. Ademais, a proximidade do diabo, que os espreitava, era incontornável, restando apenas a sua neutralização.

As justaposições continuam. A partir de Tim Ingold, é adequado reparar que a crescente literatura, ao enfrentar os temas da materialidade e da cultura material, baseia-se em uma linguagem que tenta compensar a proximidade insuficiente com os entes materiais. Durante muito tempo se afirmou que os objetos, no seu ser, permaneciam passivos em face da conceituação. O reposicionamento dos conceitos, "descrições de processos de conhecimento", conferiu a eles qualidades como "agência, intencionalidade, funcionalidade, espacialidade, semiose, espiritualidade e embodiment" (Ingold 2011 [2007]: 20). ${ }^{10}$ Essas qualidades apresentadas por Ingold fomentariam uma reificação, porque a condição passiva dos objetos permaneceria intacta em virtude da submissão deles a um novo sujeito conceitual: a agentividade.

As tentativas de alguns autores de escapar desse novo sujeito concentramse na distinção heurística entre "objeto" e "coisa" por meio das afirmações de que "a coisa não se ajusta à ordenação coerente dos objetos" (Brown 2001, apud Engelke 2007: 27); da insistência em que a coisa possui uma "bagagem teórica mínima", em lugar do "repertório teórico" congelado dos objetos (Latour 2004, apud Henare, Holbraad e Wastell 2007: 6-7); da valorização da indeterminação conceitual das coisas (um "acontecer") em detrimento das

9 Como inúmeras análises demonstraram, negligenciou-se que, em geral, os cristãos estavam (e estão) às voltas com a importância positiva ou negativa da vida no mundo e das formas materiais - e os seus desdobramentos em suas práticas devocionais - e que nem sempre a pessoa cristã originava situações pós-conversivas inerentemente individualistas (Meyer 1999; Luhrmann 2004; Engelke 2007; Coleman 2006; Keane 2007; Mosko 2010; Pels 2012; Webster 2013; Bialecki 2014, 2015). Ainda assim, esses trabalhos foram realizados entre coletivos protestantes, havendo poucas pesquisas entre católicos (Csordas 1994; Mayblin 2010; Abreu 2012; Bonfim 2012). Retomarei a discussão nas considerações finais.

10 Quanto às críticas ao conceito de "agência", ver Henare, Holbraad e Wastell (2007) e Ingold (201 1 [2007]: 28, 2012 [2010]: 33-34). Henare, Holbraad e Wastell apontam que Alfred Gell malogra em sua tentativa de considerar os objetos de arte como pessoas quando os subsume às determinações das "mentes de seus criadores" (Henare, Holbraad e Wastell 2007: 17) e, a fortiori, ao contexto social. 
cristalizações teóricas dos objetos ("fatos consumados") (Heidegger 1971, apud Ingold 2012 [2010]: 29); ou da definição da coisa como uma "dimensão extra" e refratária à "racionalidade e [à] utilidade" restritas ao objeto (Brown 2001, apud Houtman e Meyer 2012: 16). ${ }^{11}$

À primeira vista, essas considerações vão ao encontro daquilo que foi mencionado a respeito dos meus amigos: objetos podem ser passivos e ao mesmo tempo mais que isso. Ainda assim, o movimento conceitual dos objetos em direção às coisas, na literatura, caracteriza-se pelas tentativas de reatar relações com o mundo por meio da problemática da coisa. A questão modifica-se quando lidamos com pessoas que em momento algum estão às voltas com aquela reaproximação. Ao mesmo tempo, elas não deixam de assentar sua cesura em relação aos objetos, devido à inferência de que o "uso" cria uma ligação entre eles e a pessoa que pode ser explorada por intenções variadas. O uso não apenas caracteriza a submissão dos objetos à pessoa, mas é igualmente o coeficiente mínimo da proteção ou do perigo que a intenção que se agarra aos objetos pode gerar para quem os manuseia.

Em resumo, esses católicos teriam suas proposições ofuscadas caso eu me pusesse a tratá-los como se estivessem preocupados, tal como alguns analistas, com a agência ou a espiritualidade dos objetos, ou ainda com os modos como as distinções entre os objetos e as coisas têm sido repensadas. Não subestimo os rendimentos que essas reflexões proporcionam em outras situações etnográficas, mas é fundamental assinalar a especificidade dos conceitos de um modo de existência católico quando nos referimos aos objetos.

Retorno às conclusões do que é um objeto nesse mundo: "O objeto em si pode ser qualquer coisa" e/ou "qualquer coisa que seja ligada diretamente à pessoa”. Em um único golpe, essas sentenças deslocam a discussão, pois se afastam do esforço despendido para buscar a reconciliação com o mundo contida no material turn. Abrangem, ao contrário, as indeterminações e as incertezas de um modo de existência em que "intenções", benignas/malignas e conhecidas/desconhecidas, são cruciais. Por serem provenientes da etnografia, criam novas inferências devido aos limites da justaposição e das diferenças entre conceitos, "descrições de processos de conhecimento" (G. Bateson 2008 [1958]: 312), com trajetórias díspares. Alguns analistas envidam esforços para construir sua reconciliação com o cosmo, pois a separação é dada. Meus amigos empenham-se na neutralização da proximidade, porque esta é dada.

11 As considerações desses autores advêm de Martin Heidegger ou de uma leitura secundária desse mesmo filósofo por meio de Bill Brown (2001) e de Bruno Latour (2004). As aproximações e afastamentos em relação ao último são explícitas nos trabalhos de Henare, Holbraad e Wastell (2007: 7) e Ingold (2012 [2010]: 40). Na impossibilidade de aprofundar este aspecto, digo apenas que todos estão seguindo questões que sugerem mais aproximações que diferenças radicais, as quais não impediriam de colocá-los em uma mesma discussão. 


\section{INTENÇÃO, “BUSCA POR DEUS” E ASSÉDIO DO DEMÔNIO}

A última seção não nos deixa perder de vista que a remissão aos objetos no dia a dia desses católicos é dotada de uma especificidade que realça tanto a sua inércia quanto uma dimensão extra que os transforma em mais que meras mercadorias. Vimos anteriormente que importava a Ricardo mais a intenção do potencial agressor que a possível "agência" daquele objeto, a caneta. Ele não a personificava, mas sim destacava o que "une as pessoas" (Dolgin 1994, apud Strathern 2014 [1995]: 267), de modo desejável ou indesejável, a partir das suas intenções. Permanecer atento às últimas é um imperativo para se precaver de relações indeterminadas e das "ciladas do demônio". Além disso, limita as justaposições entre "conceitos teóricos" oriundos da etnografia e aqueles produzidos a partir de tentativas analíticas de "trazer as coisas de volta à vida" (Ingold 2012 [2010]).

Recordo agora de um momento da pesquisa em que conversava com um frei, cujo nome era Bento. O religioso desfiou que o demônio assedia e, posteriormente, "escraviza" as pessoas por meio de sua fraqueza. A tibiez, apesar de ser uma condição inerente à humanidade, revela-se na maioria das vezes a partir de um encontro que o maligno propicia com a finalidade de assediar. Bento prosseguiu: o demônio "coloca na sua frente [a sua fraqueza]... a bebida... a beleza [de uma mulher ou de um homem]. Ele espera que você caia na cilada. Nunca ataca diretamente. Ele arma a cilada para você. Pode ser qualquer um de nós, qualquer coisa. Ele é astuto. Ele usa as pessoas".

Se ficarmos atentos às descrições do frei, deparamos com observações já realizadas. As ponderações de Ricardo se expandem do seguinte modo: se um "objeto pode ser qualquer coisa", o diabo também pode sê-lo porque é um ser prodigioso. O assédio maligno é então habitual. Sua finalidade é "roubar a pessoa de Deus". Percebe-se que o mal ataca por meio de objetos e de pessoas contaminadas. A possibilidade da contaminação e, consequentemente, da intensificação da proximidade maligna, faz com que o objeto e a pessoa se tornem portadores de desígnios infernais no interior de seus movimentos ordinários. Bento marcava que o demônio assediava porque sabia como "alimentar a cobiça das pessoas, nem que fosse por um sapato, por uma calça, por um hábito cheiroso".

Ester era uma das pessoas mais requisitadas da Missão para orar pela cura de pessoas, católicas ou não. Certa vez, atendia em oração um jovem chamado Clayton, que passava por uma série de infortúnios: sofria com mal-estares e com frequentes acidentes enquanto conduzia sua motocicleta. A partir de "visões" proporcionadas por um dos dons do Espírito Santo, a "palavra de ciência", Ester indicou que um colega de trabalho levava para ele um "frango macumbado, consagrado ao mal". ${ }^{12}$ Desde então, Clayton começaria a buscar 
Deus e a se precaver: começou a frequentar a missa, a beber água benta, a carregar um terço no bolso e a recusar a comida. A inquietude do demônio com a proximidade de Clayton a Deus devia-se ao fato de ele estar se afastando do espiritismo; logo o ataque ocorreu através do colega de trabalho e do alimento.

Em outra ocasião, Ester afirmou que "alguns objetos [são] dados com o demônio grudado. Se você tiver muitos objetos, então é muitos objetos que ele tem". Dizia também que a ingestão de alimentos ou uso de roupas com essa presença ocasionava mal-estares, problemas humorais, brigas familiares, doenças imprevisíveis, perda de emprego etc. Chama a atenção que ela no mesmo instante concluísse: "É feito um ritual [no espiritismo] onde todos os objetos recolhidos são consagrados ao mal. É a mesma coisa que você levar uma roupa ao padre e pedir para dar a bênção de Deus, junto com aquela bênção vem cheio de coisas boas para aquela pessoa, aquela casa. Lá, é a mesma coisa, só que é o mal".

Recordo-me que, ao longo do trabalho de campo, sempre que um padre se preparava para dar a "bênção dos objetos", era possível reparar que água, fotografias, carteiras de trabalho, de identidade, bolsas, crachás de identificação, roupas, CDs, sal, chaves, telefones celulares, óleo de cozinha, uniforme e material escolares etc. eram direcionados para o altar. Entretanto, esses mesmos itens poderiam ser consagrados ao mal, tornando muito difícil definir uma classe perigosa de coisas.

Notemos que a neutralização do mal aderido ao alimento consagrado era feita por outras coisas abençoadas, tal como se passou com o regalo distribuído no casamento de Ricardo. Em geral, a definição do assédio do demônio não corresponde às imagens fantásticas que abundam em sua iconografia, mas sim à inferência de Bento de que ele pode ser qualquer coisa ou, como falava Ester, que coisas eram ofertadas com um "demônio grudado" e então "pertenciam a ele". Se itens materiais circulam, a troca corresponde também a uma proliferação de intenções.

As formas de "buscar Deus" e de ser assediado pelo demônio passam por objetos e pela existência de seres, humanos ou não, incógnitos em um mundo onde prevalece a troca de bens alienáveis. Voltando mais detidamente a Ricardo, é possível notar que ele realiza uma justaposição entre a aderência das intenções do amigo de seu amigo à caneta e a ligação das pessoas a mercadorias considerando o "uso". Retomo o célebre trecho do intelectual maori Tamati Ranaipiri analisado por Marcel Mauss:

evangélicas, alcançam o que as pessoas chamam de "superstição" e, por fim, recobrem as "fitas de santos", souvenires vendidos em sítios devocionais. A "macumba” é uma abreviatura para designar um dos lugares a partir dos quais o demônio agride alguém. Na verdade, ela muitas vezes nem é considerada quando alguém está sendo assediado por ele. Há incontáveis maneiras de realizar o cerco. 
"Vou lhes falar do hau... O hau não é o vento que sopra. De modo nenhum. Suponha que você possua um artigo determinado (taonga) e que me dê esse artigo; você me dá sem preço fixado. Não fazemos negociações a esse respeito. Ora, dou esse artigo a uma terceira pessoa que, depois de transcorrido um certo tempo, decide retribuir alguma coisa em pagamento (utu), ela me dá de presente alguma coisa (taonga). Ora, esse taonga que ela me dá é o espírito (hau) do taonga que recebi de você e que dei a ela. Os taonga que recebi pelos taonga (vindos de você), é preciso que eu os devolva" (Best 1909, apud Mauss 2003 [1925]: 198).

A implicação que se seguiu à passagem e a tornou canônica é a que segue: os taonga (artigos valiosos), na troca de presentes maori, contêm ou são o próprio "espírito da dádiva" (hau). Nota-se que a distinção entre dádiva, doador e recebedor é infactível. Isso faculta a Mauss desenvolver sua teoria sobre a feição coletiva e indispensável (obrigatória) da reciprocidade. Ele infere que "[s]e o presente recebido, trocado, obriga, é que a coisa recebida não é inerte. Mesmo abandonada pelo doador, ela ainda conserva algo dele" (Mauss 2003 [1925]: 198). Apesar das semelhanças conceituais entre as inferências de Tamati Ranaipiri e de Ricardo, é preciso que não se negligencie que mesmo o estabelecimento pela análise de um conjunto que as contenha não dilui a persistência da diferença.

A partir do próprio Mauss, e retornando à caneta ofertada para Ricardo, não é inapropriado assinalar, como já adiantamos, que a "coisa recebida não é inerte" (Mauss 2003 [1925]: 198). Contudo, ainda não é possível descrever o que ela conservaria do amigo de seu amigo. Ricardo dizia não saber qual era a intenção. Presumo que, inicialmente, há uma ação à distância que torna a caneta perigosa e que prevê também que o presente entrará em contato com o presenteado. Não é pertinente inferir, todavia, que a coisa [...] é uma "espécie de indivíduo [...] [que o] vínculo pelas coisas [...] é um vínculo de almas, pois a própria coisa tem uma alma" (Mauss 2003 [1925]: 199-200). Tomar essas considerações como dadas levaria ao apagamento das distinções que expusemos anteriormente.

O mais provável, seguindo Ricardo, é manter que "[a] pessoa que faz isso [a magia] está intencionada em fazer o mal. Tem muito mais a intenção. Você dá alguma coisa com o mal para a pessoa". A caneta não contém e tampouco é a extensão da natureza, substância e alma (Mauss 2003 [1925]: 200) daquele desconhecido que precisa ter sua intenção determinada. Reparemos que Mauss se reporta, em seguida, a algo que ficaria obscuro naquele longo excerto: “a intervenção de uma terceira pessoa [de ' $n$ ']” (2003 [1925]: 198), uma presença enigmática que parece transbordar da troca. ${ }^{13}$

13 Além dos comentários valiosos, agradeço a Ciméa B. Bevilaqua especialmente por ter me alertado para a renitência da presença de um "terceiro". Este pode ser pensado aqui como " $n$ ": qualquer quantidade indefinida ou indeterminada. 
Remeto-me a Dominique Casajus (2008 [1984]), que analisa o assunto com perspicácia.

Tamati Ranaipiri "quer falar, não de alguma coisa que A [o primeiro] dá a B [o segundo, entendido como ego], nem de alguma coisa que B deu a C [o terceiro ou " $n$ "], mas de alguma coisa que passa pelas mãos de B. Ele anuncia que vai falar de um fluxo de bens que passa por B" (Casajus 2008 [1984]: 5). O autor afirma que o maori detinha sua atenção no "fluxo de bens" que passa pelo segundo, que é o próprio narrador. O hau seria mais a qualidade que faz os bens circularem que uma propriedade deles. No caso que apresentamos, é o amigo de Ricardo que ocupa essa posição quando recebe a caneta. Estabeleço propositalmente que o fluxo, devido a uma semelhança conceitual, pode ser substituído, sem prejuízo, pela intenção.

Os dois conceitos, o fluxo e a intenção, analogamente pressupõem, da mesma maneira que o preenchimento da "escassez de contiguidade" no debate acadêmico, que algo passa, vai adiante, para comunicar. Com essa justaposição, introduzo a seguinte hipótese: uma intenção, no caso dos objetos, só poderia se atualizar passando por pessoas e por outros objetos. A analogia, entretanto, deve parar por aqui. A intenção deve ser neutralizada, interrompida, ao passo que o fluxo realça exatamente os riscos da paralisação, e a "escassez de contiguidade" refere-se à busca, no material turn, de uma continuidade perdida.

O recebimento da caneta exige, antes de tudo, que se anule a intenção do terceiro, o amigo de seu amigo. Caso se comprove que ela esteja contaminada, consagrada ao mal, a obrigação daquele que recebe, para não ser assediado pelo demônio, é perdoar seu agressor, abençoando-o em uma oração. Consagra-se o presente a Deus ou seu destino é o "lixo". A vingança motivada pelo rancor é uma armadilha do diabo, uma maneira de propiciar seu assédio. Deve-se neutralizar a raiva, uma fraqueza humana. A interrupção do malefício faz proliferar um benefício que é enviado de volta, por meio da prece ou de um objeto abençoado, para aquele que pode estar no cativeiro do demônio por conta da sua intenção.

Quando Ricardo se referia à caneta, o que o incomodava era não conhecer a "intenção do coração" do terceiro, a qual se aderia ao objeto ofertado. Impunha-se sobre a coisa, potencialmente perigosa, outra coisa, potencialmente benéfica: a água benta. Esta, como vimos, foi oferecida aos convidados do casamento com o intuito de que rezassem pelo casal, borrifassem-na em casa e no ambiente de trabalho.

Ricardo, ao dar ou receber, destacava uma questão fundamental: a lembrança de casamento foi doada para ser dissolvida, decomposta. A expectativa era que a água benta fosse dispersada e que o terço fosse usado no bolso. Não se esperava que o mimo não fosse descartado, ainda que as iniciais dos nomes de batismo dos noivos e a data da celebração estivessem afixadas no rótulo da pequena garrafa. A lembrança foi feita para ser desagregada. Seu destino, 
mesmo que não se dissesse, seria o lixo, o que não causava qualquer preocupação ou aflição.

O descarte do objeto impede que a descrição impute a ele personificação e/ou uma relação de consubstancialidade com seu proprietário. Não surpreende que a caneta seja abençoada com a água benta, o que cessa a intenção do amigo de seu amigo, assim como a tinta, que a torna um objeto utilizável, acabará. A decomposição, o uso, é o que simultaneamente movimenta intenções maléficas e benéficas, de modo que estas interrompam aquelas. Consequentemente, Ricardo dizia que não havia "nada" na água e na caneta. A circulação de objetos bentos e contaminados realça um aspecto geral do dia a dia desses católicos: eles podem conter ou reter uma intenção. Demarca menos uma qualidade intrínseca aos objetos que o fato de que uma intenção pode se juntar a eles. ${ }^{14} \mathrm{~A}$ intenção pode ser definida como uma qualidade mutável que transborda no cosmo, porque Deus "está em tudo" e o demônio "pode estar em tudo", e pelo fato inescapável de as pessoas se relacionarem umas com as outras e diariamente usarem objetos.

Essas presenças excessivas levam-me a fazer alguns apontamentos porque, conforme já foi dito, pessoas e objetos podem ser os índices materiais da intenção, devido às ocorrências que se dão em suas respectivas vizinhanças. No entanto, apenas os humanos foram, junto com o diabo, contemplados com uma doação divina inacessível aos objetos: a "vontade".

Pessoas podem "ter a intenção" de fazer o bem ou o mal ou são, mesmo sem saber, movidas por propósitos divinos ou malignos, como notou frei Bento. Ademais, tal como os objetos, podem estar abençoadas ou contaminadas. Consagrar uma pessoa não é o mesmo que consagrar um objeto, porém uma pessoa e um objeto consagrados (o colega de trabalho de Clayton e o frango que ele oferecia; o modo como Ester era um instrumento de Deus para adverti-lo da contaminação) podem ter ações com efeitos semelhantes sobre outras pessoas ou objetos. Ou seja, levam para próximo de Deus ou do demônio. Objetos são considerados bons ou prejudiciais, assim como pessoas podem trazer bênçãos

14 Foge ao escopo deste texto algo também importante: considerando que as pessoas podem levar adiante ou comunicar propósitos de Deus ou de Satanás, seria preciso determinar o regime da troca entre elas e aqueles dois seres, uma vez que se diz que a contenda que se desenrola entre os últimos é pela posse da humanidade. Mark S. Mosko (2010) afirma que o entendimento comum dos melanésios como "divíduos" também é estendível aos cristãos. Na troca dividual, pessoas transacionariam partes de si mesmas (Mosko 2010: 219). Ele conclui que Deus, Jesus, o Espírito Santo, a Virgem Maria, o diabo, os santos e os humanos são divíduos porque, no mundo cristão, humanos e não humanos são entes compósitos: suas partes provêm das trocas que estabelecem entre si (2010: 217). As assimetrias entre Deus e os humanos, contudo, não são reversíveis, o que vai de encontro à troca de perspectivas que caracteriza as permutas dividuais. Não é nem um pouco desejável, entre meus amigos, suscitar que Deus possa ficar na posição de quem está na obrigação de retribuir o que quer que seja. Colocá-lo em tal posição é tomado como um assédio demoníaco. 
ou infortúnios, seja por meio de sua intenção, seja por intenções que elas mesmas desconhecem.

É possível afirmar que pessoas e objetos, em muitos momentos, não existam como entidades autônomas, mas ajam diretamente umas sobre as outras, já que podem se tornar "instrumentos" divinos e demoníacos. Não por acaso, meus amigos se mostravam indignados quando pessoas eram "coisificadas" (como as que permaneciam em "situação de rua”), e temiam ser subjugados pelo diabo. Jubilavam, todavia, com sua própria submissão e servidão a Deus. Essa constatação analítica evita que adotemos conceitos forjados para, contrariamente, dar conta da "escassez de contiguidade" que caracterizaria a relação sujeito e mundo entre os modernos.

Se o mal ataca por meio de objetos e de pessoas contaminados, a própria noção de contaminação, nesse caso, é motor da transmissibilidade, ou seja, o objeto não é intencionado e muitas vezes a pessoa também não o é. Ao abrigar uma intenção, podem gerar outras intenções ou neutralizá-las. Se as intenções contíguas ao objeto geram outras, é porque elas definem o caráter disseminado da ação nesse mundo, entre entes divinos, infernais e humanos. Esse acoplamento faz das intenções uma instância substantiva da vida dos meus amigos, conduzindo-me assim a tecer comentários relativos à definição de pessoa nesse mundo, passando antes pelo lugar onde meus amigos se localizam em relação aos protestantes. ${ }^{15}$

\section{CONSIDERAÇÕES FINAIS}

Depois da exposição empreendida neste texto, o leitor deve estar a par de que não é conveniente afirmar, tal como sugere Brenda Carranza (2000), que "em nome do demônio" os católicos carismáticos, considerando aqueles com quem convivi, estejam criando seus oponentes cosmológicos, de modo a corroborar contendas antigas com o espiritismo, com as religiões de matriz-africana e com a maçonaria e, mais recentemente, com a Igreja Universal do Reino de Deus e a Nova Era. Essas pessoas distanciam-se da economia da "guerra espiritual" (Mariz 1999) dos pentecostais, ramo do protestantismo que mais se expandiu nas últimas décadas no Brasil. ${ }^{16}$

Clara Mafra nota que, no Brasil, a "sinceridade" pentecostal, a ênfase na subordinação do mundo aos valores imateriais e interiores transmitidos pela "palavra", teria de enfrentar a predominância de uma economia religiosa

15 Agradeço ao/à parecerista anônimo/a por essas observações e demais apontamentos que muito contribuiriam para a feitura deste texto.

16 Afastam-se, por exemplo, dos "medos racializados sobre a influência contagiosa de coisas afro" (Wirtz 2009: 495), como repara esta autora em seu trabalho acerca dos modos como, em Cuba, adeptos de religiões populares e o Estado lidam com os restos de materiais religiosos, ou seja, com o "lixo ritual". 
fundada nos aspectos da "participação" que subjaz à "santidade" católica (Mafra 2014 [201 1]: 175). A última torna mais opaca a divisão entre palavras e coisas, a própria interioridade como âmbito principal da relação com Deus e os "dualismos claramente delimitados" pelos pentecostais (2014 [2011]: 173). Aquela divisão seria perseguida em mundos protestantes, o que é realçado nos estudos de Simon Coleman (2006), Matthew Engelke (2007) e Webb Keane (2007).

Como observa Diana Espírito Santo, as análises de Keane e Coleman, quando se remetem à palavra como domínio vital da presença divina entre os protestantes, buscam dissolver "as visões normativas da linguagem como ontologicamente não interventiva" (Espírito Santo 2015: 588), reintroduzindo a importância da mediação e da materialidade nas práticas devocionais desses cristãos. Procuram afastar-se da definição moderna de religião, que diz muito a respeito das relações entre sujeito interior e ativo, mundo natural externo e inerte - a própria renitência em sentido abdutivo da "escassez de contiguidade" - e Deus situado no além ou no máximo nas crenças particulares dos adeptos.

No caso dos meus amigos, a palavra, apesar da sua importância, jamais teve essa centralidade, o que acentua uma diferença e limita qualquer justaposição entre formas de vida cristãs diversas. A análise de coletivos católicos não faz emergir os mesmos problemas e conceitos advindos das vidas de seus parentes cismáticos, os protestantes - desde sempre enredados nos paradoxos que o estabelecimento de uma relação imediata (desmaterializada) com a divindade precipita (Engelke 2007). As pessoas com quem estive reiteravam, todavia, que Deus e o diabo se manifestavam em qualquer coisa e a qualquer momento. Isso parece evidenciar uma definição específica da pessoa, em que a ação intencionada ou com propósito é reconhecida tanto em termos estritamente humanos quanto em termos de proximidade e distância com relação a Deus.

Esses católicos diziam, a todo momento, que a possibilidade de discernir se algo estava contaminado era o resultado da intimidade com a divindade. Um dos principais anseios nessa forma de vida é ser uma pessoa "próxima de Deus", que "caminha junto com" Ele. Desse modo, buscavam se precaver contra a renitência da fraqueza que aflige a pessoa "distante" da divindade, ou seja, encastelada no seu "eu" e, por isso mesmo, assediada pelo demônio.

A divindade permite que a busquem e se avizinhem a ela por meio de formas materiais. O demônio assedia as pessoas, em momentos corriqueiros da vida, por meio de formas igualmente materiais. $\mathrm{O}$ encontro entre as intenções daqueles seres e as das pessoas que usam os objetos não cria, entretanto, qualquer equivalência. Ser uma pessoa próxima de Deus se define, antes de tudo, pela neutralização da desobediência a Ele. Contiguar-se é submeter-se. O assédio do demônio consiste na tentativa de destruir essa vizinhança, que sobrepõe às intenções humanas os propósitos divinos. Se a contiguidade é o dado, a construção da distância é determinada com base em de quem se é "instrumento". 


\section{BIBLIOGRAFIA}

ABREU, Maria José A. de, 2012, "The FedEx saints: patrons of mobility and speed in a neoliberal city", em Dick Houtman e Birgit Meyer (orgs.), Things: The Religion and the Question of Materiality. Nova Iorque, Fordham University Press, 32 1-335.

APPADURAI, Arjun, 2008 [1986], "Introdução: mercadorias e a política de valor", em A. Appadurai (org.), A Vida Social das Coisas: As Mercadorias sob Uma Perspectiva Cultural. Niterói, Editora da Universidade Federal Fluminense, 15-88.

ARDENER, Edwin, 1985, "Social anthropology and the decline of modernism", em Joanna Overing, (org.), Reason and Morality. Londres, Tavistock Publication, 47-70.

ASAD, Talal, 2010 [1993], "A construção da religião como uma categoria antropológica", Cadernos de Campo, 19: 263-284.

BATESON, Gregory, 2008 [1958], Naven: Um Esboço dos Problemas Sugeridos por Um Retrato Compósito, Realizado a Partir de Três Perspectivas da Cultura de Uma Tribo da Nova Guiné. São Paulo, Editora da Universidade de São Paulo.

BATESON, Mary C., 1988, "So what's a meta for?”, em Gregory Bateson e Mary C. Bateson, Angels Fear: Towards an Epistemology of the Sacred. Nova Iorque, Bantam Books, 183-200.

BEST, Elsdon, 1909, "Maori forest lore", Transactions of the New Zealand Institute, 42: 433481.

BIALECKI, Jon, 2014, “Does God exist in methodological atheism? On Tanya Lurhmann's When God Talks Back and Bruno Latour", Anthropology of Consciousness, 25 (1): 32-52.

BIALECKI, Jon, 2015, "The judgment of God and the non-elephantine zoo: Christian dividualism, individualism, and ethical freedom after the Mosko-Robbins debate", Anthro$C y B i b$, disponível em: < http://www.blogs.hss.ed.ac.uk/anthrocybib/2015/03/17/occa sional-paper-bialecki-the-judgment-of-god-and-the-non-elephantine-zoo/ > (última consulta em junho de 2018).

BONFIM, Evandro de S., 2012, A Canção Nova: Circulação de Dons, Mensagens e Pessoas Espirituais em Uma Comunidade Carismática. Rio de Janeiro, Museu Nacional, UFRJ, tese de doutorado em Antropologia Social.

BROWN, Bill, 2001, “Thing theory”, Critical Inquiry, 28 (1): 1-22.

CANNELL, Fenella, 2005, "The Christianity of anthropology", Journal of the Royal Anthropological Institute, 11 (2): 335-356.

CANNELL, Fenella (org.), 2006, "The anthropology of Christianity”, em Fenella Cannell (org.), The Anthropology of Christianity. Durham e Londres, Duke University Press, 1-50.

CARranZA, Brenda, 2000, Renovação Carismática: Origens, Mudanças, Tendências. Aparecida, SP, Editora Santuário.

CARRANZA, Brenda, e Cecília L. MARIZ, 2009, "Novas comunidades católicas: Por que crescem?”, em Brenda Carranza et al. (orgs.), Novas Comunidades Católicas: Em Busca do Espaço Pós-Moderno. Aparecida, SP, Ideias e Letras, 139-170.

CASAJUS, Dominique, 2008 [1984], "L'énigme de la troisième personne", em Jean-Claude Galey (org.), Différences, valeurs, hiérarchie: textes offerts à Louis Dumont. Paris, Ecole des Hautes Etudes en Sciences Sociales, 1-13, disponível em: < https://halshs.archives-ouver tes.fr/halshs-00257232/document > (última consulta em junho de 2018).

CASTRO, Eduardo Viveiros de, 2002, "Xamanismo e sacrifício", em Eduardo Viveiros de Castro, A Inconstância da Alma Selvagem e Outros Ensaios de Antropologia. São Paulo, Cosac Naify, 458-472. 
COLEMAN, Simon, 2006, "Materializing the self: words and gifts in the construction of Evangelical identity", em Fenella Cannell (org.), The Anthropology of Christianity. Durham e Londres, Duke University Press, 163-184.

CORSÍN JIMÉNEZ, Alberto, e Rane WILLERSLEV, 2007, "An anthropological concept of the concept': reversibility among the Siberian Yukaghirs", Journal of the Royal Anthropological Institute, n. s., 13: 527-544.

COSTA, Ypuan Garcia, 2017, "Abertura para Deus" e "Brecha" para o Demônio: A "Libertação" entre Católicos na Cidade de São Paulo. São Paulo, Universidade de São Paulo, tese de doutorado em Antropologia Social.

CSORDAS, Thomas J., 1994, The Sacred Self: A Cultural Phenomenology of Charismatic Healing. Berkeley, University of California Press.

CSORDAS, Thomas J., 1997, Language, Charisma, and Creativity: The Ritual Life of a Religious Movement. Berkeley, University of California Press.

DOLGIN, Janet L., 1994, “The 'intent' of reproduction: reproductive technologies and the parent-child bond”, The Connecticut Law Review, 26 (4): 1261-1314.

DOUglas, Mary, 1966, Purity and Danger: An Analysis of the Concepts of Pollution and Taboo. Londres, Routledge and Kegan Paul.

ENGELKE, Matthew, 2007, A Problem of Presence: Beyond Scripture in an African Church. Berkeley, University of California Press.

ESPÍRITO SANTO, Diana, 2015, "Liquid sight, thing-like words, and the precipitation of knowledge substances in Cuban espiritismo", Journal of the Royal Anthropological Institute, n. s., $21:$ 579-596.

GARCIA, Ypuan, 2014, “A 'libertação de demônios' como cotidianidade: esboço de um estudo etnográfico", Perifèria: Revista de Recerca i Formació en Antropologia, 19 (1): 4-27.

GARRIOTT, William, e Kevin L. O’NEILL, 2008, “Who is a Christian? Toward a dialogic approach in the anthropology of Christianity”, Anthropological Theory, 8 (4): 381-398.

GELL, Alfred, 1998, Art and Agency: An Anthropological Theory. Oxford, Oxford University Press.

GELLNER, Ernest, 2003, “Concepts and society”, em Ernest Gellner, Ernest Gellner: Selected Philosophical Themes, vol. 1. Nova Iorque, Routledge, 18-46.

GREGORY, Christopher A., 1982, Gifts and Commodities. Londres, Academic Press.

HeIDEGGER, Martin, 1971, Poetry, Language, Thought. Nova Iorque, Harper and Row.

HENARE, Amiria, Martin HOLBRAAD, e Sari WASTELl, 2007, "Introduction: thinking through things”, em A. Henare, M. Holbraad e S. Wastell (orgs.), Thinking through Things: Theorising Artefacts Ethnographically. Londres e Nova Iorque, Routledge, 1-31.

HOUTMAN, Dick, e Birgit MEYER, 2012, "Introduction: material religion, how things matter”, em D. Houtman e B. Meyer (orgs.), Things: The Religion and the Question of Materiality. Nova Iorque, Fordham University Press, 1-23.

INGOLD, Tim, 2006, "Rethinking the animate, re-animating thought", Ethnos, 71 (1): 9-20. INGOLD, Tim, 2011 [2007], "Materials against materiality", em T. Ingold, Being Alive: Essays on Movement, Knowledge and Description, Londres e Nova Iorque, Routledge, 19-32. INGOLD, Tim, 2012 [2010], "Trazendo as coisas de volta à vida: emaranhados criativos num mundo de materiais”, Horizontes Antropológicos, 18 (37): 25-44.

KEANE, Webb, 1997, "Religious language", Annual Review of Anthropology, 26: 47-71.

KEANE, Webb, 2007, Christian Moderns: Freedom and Fetish in the Mission Encounter. Berkeley, University of California Press. 
LAIDLAW, James, 2000, "A free gift makes no friends", Journal of the Royal Anthropological Institute, n.s., 6: 617-634.

LATOUR, Bruno, 1994 [1991], Jamais Fomos Modernos: Ensaio de Antropologia Simétrica. Rio de Janeiro, Editora 34.

LATOUR, Bruno, 2000a [1987], Ciência em Ação: Como Seguir Cientistas e Engenheiros Sociedade Afora. São Paulo, Editora da UNESP.

LATOUR, Bruno, 2000b, "Factures/fractures: de la notion de réseau à celle d'attachement", em André Micoud e Michel Peroni (orgs.), Ce que nous relie. La Tour d'Argues, Editions de l'Aube, 1-17, disponível em < http://www.bruno-latour.fr/sites/default/files/76-FAKTU RA-FR.pdf $>$ (última consulta em junho de 2018).

LATOUR, Bruno, 2001 [1999], A Esperança de Pandora: Ensaios sobre a Realidade dos Estudos Científicos. Bauru, SP, Edusc.

LATOUR, Bruno, 2004, "Why has critique run out of steam? From matters of fact to matters of concern”, Critical Inquiry, 30: 225-248.

LÉVI-STRAUSS, Claude, 2008 [1962], O Pensamento Selvagem. Campinas, SP, Papirus.

LUHRMANN, Tanya M., 2004, "Metakinesis: how God becomes intimate in contemporary US Christianity”, American Anthropologist, 106 (3): 518-528.

MAFRA, Clara, 2014 [2011], "Santidade e sinceridade na formação da pessoa cristã", Religião e Sociedade, 34 (1): 173-192.

MARIZ, Cecília L., 1999, "A teologia da batalha espiritual: uma revisão da bibliografia", Revista Brasileira de Informação Bibliográfica em Ciências Sociais, 47: 33-48.

MARIZ, Cecília L., 2006, "Comunidades de vida no Espírito Santo: um novo modelo de família?”, em Luiz Fernando Dias Duarte et al. (orgs.), Família e Religião. Rio de Janeiro, Contra Capa, 263-286.

MAUSS, Marcel, 2003 [1925], "Ensaio sobre a dádiva: forma e razão da troca nas sociedades arcaicas”, em M. Mauss, Sociologia e Antropologia. São Paulo, Cosac Naify, 183-314.

MAYBLIn, Maya, 2010, Gender, Catholicism, and Morality in Brazil: Virtuous Husband, Powerful Wives. Nova Iorque, Palgrave Macmillan.

MEYER, Birgit, 1999, Translating the Devil: Religion and Modernity among the Ewe in Ghana. Trenton e Asmara, Africa World Press.

MOSKO, Mark S., 2010, "Partible penitents: dividual personhood and Christian practice in Melanesia and the West", Journal of the Royal Anthropological Institute, n.s., 16: 215-240.

PELS, Peter, 2012, "The modern fear of matter: reflections on the Protestantism of Victorian science", em Dick Houtman e Birgit Meyer (orgs.), Things: The Religion and the Question of Materiality. Nova Iorque, Fordham University Press, 27-39.

ROBBINS, Joel, 2003, "What is a Christian? Notes toward an anthropology of Christianity”, Religion, 33 (3): 191-199.

ROBBInS, Joel, 2004, Becoming Sinners: Christianity and Moral Torment in a Papua New Guinean Society. Berkeley, University of California Press.

ROBBINS, Joel, 2007, "Continuity thinking and the problem of Christian culture: belief, time, and the anthropology of Christianity", Current Anthropology, 48 (1): 5-38.

ROBBINS, Joel, 2011 , "Transcendência e antropologia do cristianismo: linguagem, mudança e individualismo", Religião e Sociedade, 31 (1): 11 -31.

STRATHERN, Marilyn, 2013 [1990], "Artifacts of history: events and the interpretation of images", em M. Strathern, Learning to See in Melanesia. Manchester, HAU Society for Ethnographic Theory, 157-178. 
STRATHERN, Marilyn, 2014 [1995], "A relação: acerca da complexidade e da escala", em

M. Strathern, O Efeito Etnográfico e Outros Ensaios. São Paulo, Cosac Naify, 263-294.

VELHO, Otávio, 2007 [2002], "Mudanças epistemológicas e os estudos da religião", em

O. Velho, Mais Realistas do que o Rei: Ocidentalismo, Religião e Modernidades Alternativas. Rio de Janeiro, Topbooks, 372-338.

WEBER, Max, 1987 [1904], A Ética Protestante e o Espírito do Capitalismo. São Paulo, Livraria Pioneira Editora.

WEBSTER, Joseph, 2013, "The immanence of transcendence: God and the Devil on the Aberdeenshire coast”, Ethnos, 78 (3): 380-402.

WIRTZ, Kristina, 2009, "Hazardous waste: the semiotics of ritual hygiene in Cuban popular religion”, Journal of the Royal Anthropological Institute, n.s., 15: 476-501.

Receção da versão original / Original version

Receção da versão revista / Revised version

Aceitação / Accepted
$2015 / 12 / 28$

$2017 / 08 / 25$

$2018 / 01 / 31$ 